\title{
Estimation of the quantity of aeolian saltation sediments blown into the Yellow River from the Ulanbuh Desert, China
}

\author{
HeQiang DU*, Xian XUE, Tao WANG \\ Cold and Arid Regions Environmental and Engineering Research Institute, Chinese Academy of Sciences, Lanzhou 730000, China
}

\begin{abstract}
The Ulanbuh Desert borders the upper reach of the Yellow River. Every year, a mass of aeolian sand is blown into the Yellow River by the prevailing wind and the coarse aeolian sand results in serious silting in the Yellow River. To estimate the quantity of aeolian sediments from the Ulanbuh Desert blown into the Yellow River, we simulated the saltation processes of aeolian sediments in the Ulanbuh Desert. Then we used a saltation submodel of the IWEMS (Integrated Wind-Erosion Modeling System) and its accompanying RS (Remote Sensing) and GIS (Geographic Information System) modules to estimate the quantity of saltation sediments blown into the Yellow River from the Ulanbuh Desert. We calibrated the saltation submodel by the synchronous observation to wind velocity and saltation sediments on several points with different vegetation cover. The vegetation cover, frontal area of vegetation, roughness length, and threshold friction velocity in various regions of the Ulanbuh Desert were obtained using NDVI (Normalized Difference Vegetation Index) data, measured sand-particle sizes, and empirical relationships among vegetation cover, sand-particle diameters, and wind velocity. Using these variables along with the observed wind velocities and saltation sediments for the observed points, the saltation model was validated. The model results were shown to be satisfactory (RMSE less than 0.05 and $\left|R_{e}\right|$ less than $17 \%$ ). In this study, a subdaily wind-velocity program, WINDGEN, was developed using this model to simulate hourly wind velocities around the Ulanbuh Desert. By incorporating simulated hourly wind-velocity and wind-direction data, the quantity of saltation sediments blown into the Yellow River was calculated with the saltation submodel. The annual quantity of aeolian

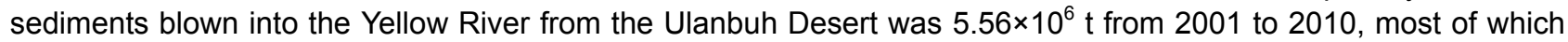
occurred in spring (from March to May); for example, $6.54 \times 10^{5}$ tons of aeolian sand were blown into the Yellow River on 25 April, 2010. However, in summer and winter, the saltation process occasionally occurred. This research has supplied some references to prevent blown sand hazards and silting in the Yellow River.
\end{abstract}

Keywords: aeolian sand sediments; integrated wind-erosion modeling system; NDVI; WINDGEN; Ulanbuh Desert

Citation: HeQiang DU, Xian XUE, Tao WANG. 2014. Estimation of the quantity of aeolian saltation sediments blown into the Yellow River from the Ulanbuh Desert, China. Journal of Arid Land, 6(2): 205-218. doi: 10.1007/s40333-013-0198-3

Wind erosion is an internationally recognized land degradation issue that affects $28 \%$ of the global land area (Oldeman, 1994; Callot et al., 2000; Prospero et al., 2002; Webb et al., 2006). The calculation of wind erosion begins with a determination of the sand (dust) flux from the surface. The sand flux is affected by soil, vegetation, and wind regime. Initially, researchers considered only the impact of wind velocity. For example, Bagnold (1941) proposed a cubic relationship between friction velocity and horizontal sand flux. Since then, many studies have explored various processes and characteristics from both empirical and theoretical perspectives (Owen, 1964; Anderson and Haff, 1991; Shao and Li, 1999; Dong et al., 2000; Mckenna Neuman, 2003; Mu et al., 2003; Okin, 2005; Baas and Nield, 2007; Baddock et al., 2007; Reffet et al., 2010). The Integrated Wind-Erosion Modeling System (IWEMS) (Lu and Shao, 2001), the Wind Ero-

*Corresponding author: HeQiang DU (E-mail: dilikexue119@163.com)

Received 2013-01-08; revised 2013-06-24; accepted 2013-07-24

(C) Xinjiang Institute of Ecology and Geography, Chinese Academy of Sciences, Science Press and Springer-Verlag Berlin Heidelberg 2014 
sion on European Light Soils (WEELS) system (Böhner, 2003), the Texas Tech Erosion Analysis (TEAM) system (Gregory et al., 2004), the Wind Erosion Stochastic Simulator (WESS) (Van Pelt et al., 2004), the Revised Wind Erosion Equation (RWEQ) (Visser et al., 2005), and the Wind Erosion Prediction System (WEPS) are examples of wind-erosion models that were designed for wind-erosion researches and landmanagement applications (Hagen, 1991; Coen et al., 2004).

Wind-erosion models can be divided roughly into empirically and physically based models (Webb et al., 2006). Empirical models usually establish relationships between the sand flux and wind velocity, sand-particle size, vegetation cover, soil moisture, and other variables (Dong et al., 1999). Such models are still being extensively used because of their simple structure and ease of use. The Wind Erosion Equation (WEQ) and the Revised Wind Erosion Equation (RWEQ) are widely used empirical models (Woodruff and Siddoway, 1965; Fryrear et al., 1998). These have been used to estimate wind erosion in an area as a simple product of empirical coefficients. In the absence of a theoretical basis and a physical process description, these empirical models have been limited in widespread application. On the contrary, physically based models can describe in detail the physical mechanisms of sediment yields and can simulate the individual components of the entire erosion process by solving the corresponding equations. Such models are also generally better for assessing both the spatial and temporal variability of natural wind-erosion processes. The Wind Erosion Prediction System (WEPS) is a physically based model that simulates sediments yield and deposition using a spatially and temporally distributed approach (Hagen, 1991). Although this model has been considered as the most advanced among numerous wind-erosion models, it is complex, data-intensive, beyond the capability of environmental scientists to adjust or modify, and also limited in its ability to take advantage of GIS.

The Integrated Wind-Erosion Modeling System (IWEMS) is also a physically based model which can predict wind erosion quantitatively from local to global scales. The model has some advantages such as a simple modeling process and fewer input parameters. An obvious advance is that it integrates remote sens- ing and GIS databases (Shao, 2008), which can significantly increase the data updating rate. It is appropriately used in regions lacking sufficient observed data.

The Ulanbuh Desert borders the Yellow River. Every year, a mass of aeolian sand is blown into the Yellow River, resulting in serious silting which threatens the operation of Sanshenggong Hydro-Junction, which is an important water conservation project in Dengkou county, Inner Mongolia. Previous researchers have estimated that $1.78 \times 10^{7} \mathrm{t}$ of aeolian sediments were blown into the Yellow River annually from 1958 to 1989 (Yang et al., 1987). Until 2000, the annual quantity of aeolian sediments blown into the Yellow River was as much as $2.86 \times 10^{7} \mathrm{t}$ ( $\mathrm{He}$ et al., 2011). Yao et al. (2008) determined the area of aeolian desert in the Ningxia-Inner Mongolia regions that supplied the aeolian sand blowing into the Yellow River by comparing sequential satellite imageries of $1977,1990,2000$, and 2008, and they found that the total area of river-bank erosion from 1958 to 2008 was equal to $518.38 \mathrm{~km}^{2}$. Large quantities of aeolian sediments have been deposited in the Yellow River, resulting in riverbed silting and a decrease in the capacity of Sanshenggong Reservoir. The available storage of Sanshenggong Reservoir is now only $40.2 \%$ of its designed capacity because of the aeolian sediments in the reservoir.

The previous estimates mentioned above used the method of sediments balance or comparison of remote sensing images (Yang et al., 1987; Yao et al., 2008; He et al., 2011). However, the temporal resolutions of these estimates are all limited, and therefore these studies could determine only approximately the quantity of sediments that silted into the Yellow River over a period of time, and moreover the specific location and time of the aeolian process could not be obtained by these methods. Based on this situation, the local governments could not know where blown-sand protection projects should be built. Considering the shortcomings of previous studies and the lack of observed data from the Ulanbuh Desert, in this paper, the IWEMS wind-erosion model proposed by Shao (2001) was used to simulate daily saltation in the Ulanbuh Desert and to estimate the quantity of aeolian saltation sand that was blown into the Yellow River. Through this simulation, the spatial and temporal distribution of 
saltation in the Ulanbuh Desert would be obtained. We hope that this research can provide some references for building a defense system against blown sand from the Ulanbuh Desert.

\section{Study area}

The Ulanbuh Desert is located in the western part of Inner Mongolia, China. It borders the Yellow River and extends about $150 \mathrm{~km}$ from Wuhai city to Dengkou county, and its terrain slopes gently from northwest to southeast, which is approximately identical to the directions of main wind and dune migration. The Ulanbuh Desert, with an altitude of 1,028-1,054 m asl, has an area of $1.3 \times 10^{4} \mathrm{~km}^{2}$ (Fig. 1). Mobile dunes, mainly of the transversal type, account for $80 \%$ of its area, and the highest ones are up to $17 \mathrm{~m}$ in height. The surface is covered by loose sand, and more than $90 \%$ of the surface sand particles are fine sand $(0.10-0.25 \mathrm{~mm})$. The climate of this region is inhospitable, with low rainfall, strong evaporation and frequent wind. From 1956 to 2010, the annual average temperature was $8.4^{\circ} \mathrm{C}$, the highest temperature was $32.9^{\circ} \mathrm{C}$, and the lowest temperature was $-27^{\circ} \mathrm{C}$. The annual precipitation was approximately $150 \mathrm{~mm}$, $60 \%-70 \%$ of which occurs from July to September. The annual evaporation can reach $2,372 \mathrm{~mm}$. Strong winds occur frequently in the spring months (March-June), and diurnal maximum wind velocities greater than $10 \mathrm{~m} / \mathrm{s}$ at a height of $10 \mathrm{~m}$ occurred more than 30 times per year from 1961 to 2010 .

\section{Methodology and scenarios}

\subsection{Model description}

The IWEMS submodel links the dynamic saltation-emissions model with GIS and RS technology, which provides the necessary input parameters for this

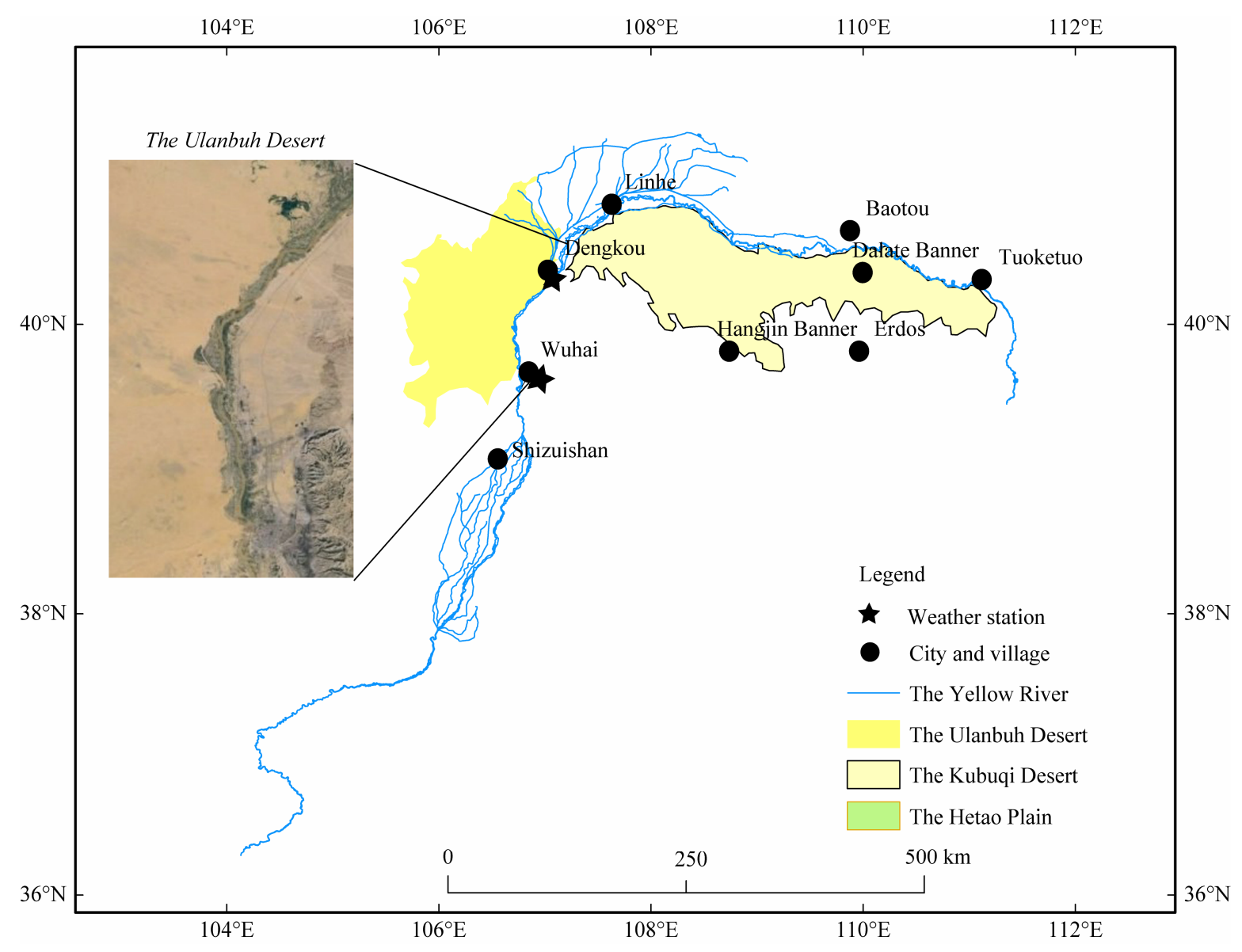

Fig. 1 Geomorphic types and city distribution of the study area 
model. This model includes two key parameters representing (1) the saltation threshold friction velocity $\left(u *_{t}\right)$ and $(2)$ the streamwise saltation flux $(Q)$.

\subsubsection{Threshold friction velocity}

The driving forces for the liftoff of sand particles are aerodynamic drag and aerodynamic lift, which are related to the wind shear stress near the surface and hence are functions of the friction velocity $(u *)$. The threshold friction velocity $\left(u_{*}\right)$ is the minimum friction velocity required for the aerodynamic forces to overcome the retarding forces, namely the gravity force and the interparticle cohesive force, and to initiate the movement of soil particles. Under ideal conditions, $u_{*_{t}}$ can be expressed as a function of the particle size $d$. Several theories have been derived for sand with uniform and spherical particles spread loosely over a dry and unsheltered surface (Bagnold, 1941; Greeley and Iversen, 1985; Shao and Lu, 2000; McKenna, 2003).

However, the desert surface is normally covered by sparse vegetation, which has a noticeable effect on the threshold friction velocity. The threshold friction velocity with vegetation can be expressed as:

$$
u_{*_{\mathrm{t}}}\left(d_{s} ; \lambda\right)=u_{*_{\mathrm{t}}}\left(d_{s}\right) f_{\lambda}(\lambda) .
$$

Where $u *_{t}\left(d_{s} ; \lambda\right)$ denotes the threshold friction velocity of sand particles with diameter $d_{s}$ in the presence of vegetation; $\lambda$ is the frontal area of the roughness element; $f_{\lambda}(\lambda)$ is the function that modifies the threshold friction velocity to reflect the roughness elements; and $u *_{*}\left(d_{s}\right)$ is the threshold friction velocity under the ideal condition that the surface is covered by loose sand particles of uniform and spherical shape. The threshold friction velocity under ideal conditions, $u_{*}\left(d_{s}\right)$, can be expressed by an equation proposed by Shao (2001):

$$
u_{*_{t}}\left(d_{s}\right)=\sqrt{a_{1}\left(\frac{\rho_{p}}{\rho_{a}} g d_{s}+\frac{a_{2}}{\rho_{a} d_{s}}\right)} .
$$

Where $\rho_{a}$ and $\rho_{p}$ are the densities of air and of sand particles, 1.29 and $2,600 \mathrm{~kg} / \mathrm{m}^{3}$ respectively; $g$ is the acceleration of gravity, $9.8 \mathrm{~m} / \mathrm{s}^{2} ; a_{1}$ is a dimensionless parameter; and $a_{2}$ is a dimensioning parameter. Shao (2001) suggested values of $a_{1}=0.0123$ and $a_{2}=3 \times 10^{-4}$ $\mathrm{kg} / \mathrm{s}^{2}$ for these parameters. Equation 2 implies that $u *_{t}$ is generally proportional to $\sqrt{Y_{1} d+Y_{2} d^{-1}}$ rather than to $\sqrt{d}$, where $d$ denotes the diameters of sand particles. The $Y_{2} d^{-1}$ term arises from the effect of interparticle cohesion. For uniform sand, Raupach et al. (1993) derived and experimentally verified an expression for the roughness length-correction function $f_{\lambda}$, which is the ratio between the threshold friction velocity with roughness elements, $u_{*_{t}}\left(d_{s}, \lambda\right)$, and the velocity without roughness elements, $u *_{*}\left(d_{s}\right)$ :

$$
f_{\lambda}=\frac{u_{*_{t}}\left(d_{s}, \lambda\right)}{u_{*_{t}}\left(d_{s}\right)}=\left(1-m_{r} \sigma_{r} \lambda\right)^{1 / 2}\left(1+m_{r} \beta_{r} \lambda\right)^{1 / 2} .
$$

Where $m_{r}$ is a tuning parameter with a value less than one which accounts for non-uniformities in the surface stress distribution; $\sigma_{r}$ is the ratio of basal area to frontal area $\left(\sigma_{r}=\eta / \lambda\right)$; and $\beta_{r}=C_{r} / C_{s}$ is the ratio of the pressure-drag coefficient to the friction-drag coefficient. Raupach et al. (1993) recommended values of $\beta_{r} \approx 90$, $m_{r}=0.5$, and $\sigma_{r}=1$. This predictive equation well represents the wind-tunnel observations of $f_{\lambda}$ reported by Marshall (1971), Lyles and Allison (1976), and Gillette and Stockton (1989), as well as the field data of Musick and Gillette (1990).

Although soil moisture and physical crust are also important factors in the threshold friction velocity calculation, their effects were neglected here to simplify the model because during the periods when wind erosion primarily occurs (spring), the precipitation is very low, resulting in low moisture content in the sands and the presence of small and discontinuous physical crusts.

\subsubsection{Streamwise saltation flux}

The streamwise saltation flux for a soil of uniform particle size $d_{s}$ can be estimated using Owen's model:

$$
Q\left(d_{s}\right) \begin{cases}\frac{c_{o} A_{e} \rho u_{*}^{3}}{g}\left[1-\left(\frac{u_{*_{t}}}{u_{*}}\right)^{2}\right] & \left(u_{*} \geq u_{*_{i}}\right) . \\ 0 & \left(u_{*}<u_{*_{i}}\right)\end{cases}
$$

Where $u_{* t}$ can be estimated using Eqs. $1-3$, and $A_{e}$ is the fraction of erodible area. The Owen coefficient, $c_{o}$, has some associated uncertainties. In theory, $c_{0}$ is not a constant, but depends on the rate of a sand particle's ultimate velocity to the friction wind velocity. Owen (1964) proposed that $c_{\mathrm{o}}$ should equal $0.25+\omega_{t}\left(d_{s}\right) / 3 u *$ in the original formulation, and that $\omega_{t}$ should denote a sand particle's ultimate velocity. Typical values of $c_{0}$ are close to one, but with a considerable scatter.

The model presented above is based on the assumption that the sand particles are uniform. In reality, sand particles in nature are of multiple sizes, which violate 
the assumption and make it difficult to assign a meaning to the concept of threshold friction velocity. In this study, a useful simplifying assumption was introduced, that the particles fall into different size groups which saltate independently (Shao, 2008). The assumption can be expressed by saying that a surface covered by a mixture of particles of different sizes is considered to be identical to a well-sorted surface and that particles of different sizes saltate independently.

Based on the theory of independent saltation, we calculated the sand flux over the natural surface in the study area:

$$
Q=\sum_{d_{1}}^{d_{2}} Q\left(d_{s}\right) \times p\left(d_{s}\right)
$$

Where $d_{1}$ and $d_{2}$ denote the upper and lower limits of saltation particle size for a given $u *$ and $p\left(d_{s}\right)$ is the fraction of particles with diameter $d_{s}$.

By integrating wind velocity, sand particle sizes, and vegetation frontal area, saltation emissions in different regions over various periods of time can be calculated.

The saltation sediments yields deposited in the Yellow River were estimated using the distribution of saltation emissions and the proportions of saltation emissions in different directions. The resulting equation can be written as:

$$
q_{d}=q_{s} \times \sum_{i=1}^{16} f_{q i} \times|\sin \alpha| .
$$

Where $q_{d}$ denotes the amount of saltation sediments that deposit in the Yellow River, $q_{s}$ is the saltation emissions, $f_{q i}$ is the fraction of saltation emissions in the $i^{\text {th }}$ direction, and $\alpha$ is the intersection angle between the saltation direction and the Yellow River.

\subsubsection{Hourly mean wind velocity}

From meteorological data recorded at the two weather stations, it was clear that the average diurnal wind velocity was far less than the threshold wind velocity for sand saltation. If these diurnal average wind-velocity values were used to model saltation emissions in the Ulanbuh Desert, modeled saltation sediment values far less than the actual sediment values would be obtained. To eliminate the model error caused by using diurnal average wind velocities, it is necessary to simulate the hourly mean wind velocity around the Ulanbuh Desert.

In this study, the WINDGEN program of WEPS
(Wind Erosion Prediction System) was introduced (Skidmore and Tatarko, 1990). WINDGEN is a subdaily wind-velocity generator and will be calculated whenever the maximum wind velocity for the day exceeds a set erosion threshold. The method of hourly wind-velocity calculation can be stated as follows:

$$
\begin{gathered}
u_{\text {rep }}=\frac{\left(u_{\max }+u_{\min }\right)}{2}, \\
u_{\text {ratio }}=\frac{u_{\max }}{u_{\min }} .
\end{gathered}
$$

Where $u_{\max }$ is the daily maximum wind velocity, $\mathrm{m} / \mathrm{s}$; $u_{\min }$ is the daily minimum wind velocity, $\mathrm{m} / \mathrm{s} ; u_{\text {req }}$ is the daily mean representative wind velocity, $\mathrm{m} / \mathrm{s}$; and $u_{\text {ratio }}$ is the ratio of daily maximum to daily minimum wind velocity. Wind velocity for any hour of the day $u(i)$ can be simulated as:

$$
\begin{aligned}
& u(i)=u_{\mathrm{rep}}+0.5\left(u_{\max }-u_{\min }\right) \\
& \cos \left[2 \pi\left(24-h r_{\max }+i\right) / 24\right] .
\end{aligned}
$$

Because daily minimum wind velocities are difficult to obtain from the national weather station, the daily average wind velocity $u$ was used instead of the daily mean representative wind velocity $u_{\text {rep. }}$ Then the daily minimum wind velocity, $u_{\min }$, can be written as:

$$
u_{\min }=2 u-u_{\max } \text {. }
$$

If the daily maximum wind velocity is larger than the diploid average wind velocities, it was assumed that the daily minimum wind velocity was zero, because wind velocity cannot be a negative value. By integrating Eqs. 8-10, we calculated the hourly wind velocity.

\subsubsection{Method of model evaluation}

The simulated values can be evaluated by direct comparison with observations. In this study, two statistical parameters have been proposed to evaluate the model results. The root mean square error (RMSE) and the deviation $\left(R_{e}\right)$ were computed as criteria for goodness of fit.

The RMSE (Thomann, 1982) is defined as:

$$
R M S E=\left(\frac{\sum_{i=1}^{n}\left(O_{i}-P_{i}\right)^{2}}{n}\right)^{1 / 2} .
$$

Where $Q_{i}$ and $P_{i}$ are the observed and predicted values for the $i^{\text {th }}$ pair and $n$ is the total number of paired values. The smaller the RMSE, the closer the simulated 
values are to the observed values.

The deviation of the sand-flux values is given by the following equation (Yen, 1993):

$$
R_{e}=\left(\frac{P_{i}-O_{i}}{O_{i}}\right) \times 100 \% .
$$

The smaller the absolute value of $R_{e}$, the better are model results.

\subsection{Scenarios}

Because published research results and observations about aeolian processes in the Ulanbuh Desert are rare, remote sensing data, geographic information system technology, meteorological data, and field observations were integrated to develop this saltation model.

\subsubsection{Meteorological data}

Meteorological data recorded at Wuhai station $\left(39^{\circ} 68^{\prime} \mathrm{N}, 106.8^{\prime} \mathrm{E}\right)$ and Dengkou station $\left(40^{\circ} 33^{\prime} \mathrm{N}\right.$, $\left.107.0^{\prime} \mathrm{E}\right)$ in Inner Mongolia from 2001 to 2010 were collected (Fig. 1). These data include precipitation, average wind velocity, maximum wind velocity, and wind direction, and the temporal resolution of the data is diurnal. Because wind velocity is gusty and wind direction is capricious, it was difficult to obtain accurate interpolated wind field data.

The study area can be divided into two parts. To the south of Yishuntaogaile village, the river direction is from south to north; and in the northern part of the village, the river direction changes to run from southwest to northeast (Fig. 1). Based on this situation, Yishuntaogaile village was set as the demarcation point. To the south of this point, the wind velocity data recorded by Wuhai station were used, and to the north, the data recorded by Dengkou station were used.

\subsubsection{Remote sensing data}

Remote sensing data, including normalized difference vegetation index $(N D V I)$ data and land-use data, were used in this research. NDVI is extensively used to monitor changes in vegetation (Wang et al., 2004; Omuto et al., 2010; Mkhabela et al., 2011; Mangiarotti et al., 2012). The NDVI can be expressed as:

$$
N D V I=\frac{\rho_{\text {nir }}-\rho_{\text {red }}}{\rho_{\text {nir }}+\rho_{\text {red }}} .
$$

Where $\rho_{\text {nir }}$ is the reflectance of near-infrared radiation and $\rho_{\text {red }}$ is the reflectance for red.

In this study, the Moderate Resolution Imaging Spectroradiometer (MODIS) NDVI products (16 days, $250 \mathrm{~m}$ ) and the SPOT-VEGATATION NDVI data set (10 days, 1,000 m) from 1 January, 2001 to 31 December, 2010 were downloaded (http://ladsweb.nascom.nasa.gov/data/search.html; http://free.vgt.vito.be/). Based on these two kinds of data, a data set with spatial resolution of $250 \mathrm{~m}$ and time resolution of 10 days was compiled.

Land-use data were obtained by human-computer interaction and visual interpretation of TM and ETM+ images of the Ulanbuh Desert taken in 2000. To extract information from the images, a combination of wavelength bands of 4,3 , and 2 was identified to produce false-color images. These bands are most sensitive to vegetation and soil moisture. To identify land-use types, a set of criteria for judging land-use category was used (Table 1). On the basis of these criteria, the ArcGIS image processing software was used to interpret the TM and ETM images by means of supervised classification. The visual information was interpreted automatically based on blended image

\begin{tabular}{|c|c|c|}
\hline Land use type & Image characteristics & Other characteristics \\
\hline Dry farmland & $\begin{array}{l}\text { Linear borders and gridding; bright red or } \\
\text { light red color }\end{array}$ & $\begin{array}{l}\text { Clear linear objects such as roads and live- } \\
\text { stock enclosures }\end{array}$ \\
\hline Forest & Irregular shape; red, henna, or brown color & Red and green ridges, strip along a river \\
\hline Grassland & $\begin{array}{l}\text { Large areas with irregular shape; pink, red, } \\
\text { and off-white colors }\end{array}$ & Patches of bare soil \\
\hline River & Winding, slender; blue, indigo, or cyan & Thin and winding; homogeneous color \\
\hline Fluvial marsh & $\begin{array}{l}\text { Linear strips; usually homogeneous white } \\
\text { color }\end{array}$ & Usually found along a river \\
\hline Residential area & $\begin{array}{l}\text { Regular geometry; blue, ash, or light blue } \\
\text { color }\end{array}$ & Blurry boundary \\
\hline Sandy land & $\begin{array}{l}\text { Meniscus, gridded or irregular shapes, with } \\
\text { undulating patterns; light yellow, brown, or } \\
\text { ash color }\end{array}$ & Distinct boundaries; homogeneous color \\
\hline
\end{tabular}

Table 1 Interpretation criteria for the classification of land use type 
elements and knowledge of the actual land surface. The smallest image spot is a $6 \mathrm{~m} \times 6 \mathrm{~m}$ image element. To simplify the data input process described below, fewer types of land use were included than in the common standard land-use classification system. The seven land-use types used in the interpretation are farmland, forest, grassland, river, fluvial marsh, residential area, and sandy land. Because the farmland along the Yellow River has higher soil moisture content and a mass of soil aggregates, little saltation sand flux was generated in the farmland in this region. Therefore, in this study, grassland, fluvial marsh, and sandy land along the Yellow River were considered as the aeolian sediments sources for the river.

\subsubsection{Observed and calculated data}

The observed and calculated data included surface sand particle sizes, roughness lengths on different surfaces, vegetation covers, plant heights, wind velocities, and quantities of aeolian sediments. Sand-particle samples were first taken from the field with three repetitions in a quadrat with an area of $10 \mathrm{~cm} \times 10 \mathrm{~cm}$ and a depth of $5 \mathrm{~cm}$; in total, 100 sand-particle size samples were collected. In the laboratory, remains of dead animals and plants were wiped off, and the sand-particle samples were sieved using an automatic sieve shaker that could process 10 sieves at one time, with every sieving lasting for $15 \mathrm{~min}$. Following this, the size of the sand particles was measured (Fig. 2).

The height, frontal area, and cover of vegetation were observed using sample-plot surveys and image processing. Using the sample-plot survey method, the heights of the vegetation were measured. Photos of the vegetation in the quadrats in different directions and at different heights from its lowest point to its peak were

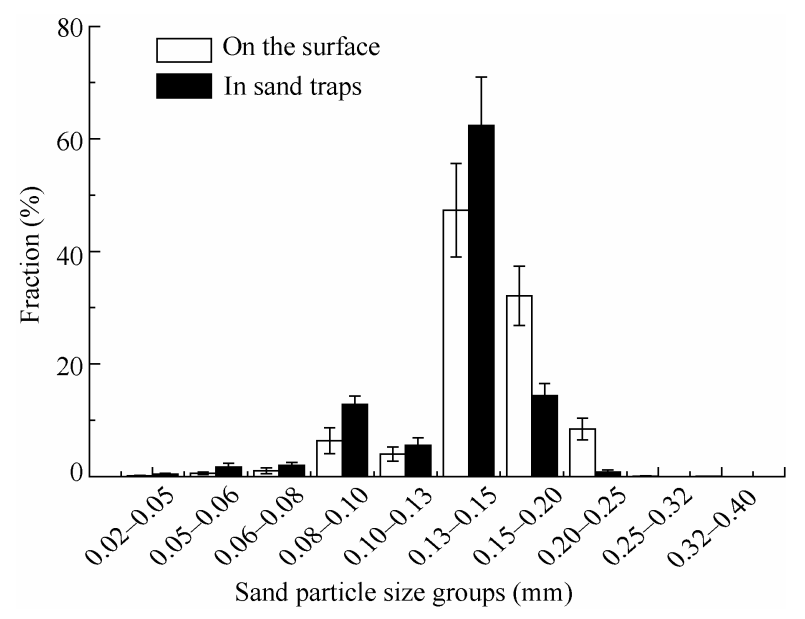

Fig. 2 Particle-size distribution in the Ulanbuh Desert, mean \pm S.E.

taken using a digital camera. To determine the differences in gray tone between the plants and the interstices between the stems, these photos were digitized using the ERDAS IMAGING 9.1 image-processing software, following which the vegetation and interstices were classified using the unsupervised classification method. Based on the fraction of pixels occupied by vegetation, the frontal area and the vegetation cover of every quadrat were calculated. In this study, nine quadrats were surveyed, yielding sightings of seven species in the Ulanbuh Desert (Table 2).

Wind velocity was measured using a mobile anemobiagraph station produced by Met One Instruments, Inc., which includes one wind direction sensor (024A) and eight wind velocity sensors (014A) operating at one-minute intervals. The wind direction sensor was placed at a height of $200 \mathrm{~cm}$, and wind velocity sensors were installed at heights of 10, 20, 30, 40, 50, 100,

Table $2 N D V I$, vegetation cover $(V C)$, frontal area $(\lambda)$, vegetation height $(h)$, and roughness length $\left(z_{0}\right)$ of different species in the Ulanbuh Desert

\begin{tabular}{|c|c|c|c|c|c|}
\hline Species & $N D V I$ & $V C$ & $\lambda$ & $h(\mathrm{~m})$ & $z_{0}(\mathrm{~m})$ \\
\hline Seriphidium terrae-albae & 0.148 & 0.1225 & 0.5431 & 0.5400 & 0.0073 \\
\hline Seriphidium terrae-albae & 0.150 & 0.1231 & 0.5451 & 0.6396 & 0.0059 \\
\hline Seriphidium terrae-albae & 0.112 & 0.1043 & 0.4868 & 0.6640 & 0.0051 \\
\hline Artemisia ordosica & 0.163 & 0.1343 & 0.5765 & 0.6338 & 0.0074 \\
\hline Artemisia ordosica & 0.116 & 0.1136 & 0.5165 & 0.5595 & 0.0065 \\
\hline Artemisia ordosica & 0.116 & 0.0930 & 0.4485 & 0.3133 & 0.0064 \\
\hline Artemisia ordosica & 0.142 & 0.1132 & 0.5153 & 0.4945 & 0.0059 \\
\hline Artemisia ordosica & 0.100 & 0.0972 & 0.4628 & 0.4973 & 0.0058 \\
\hline Wheatgrass & 0.090 & 0.0766 & 0.3872 & 0.0500 & 0.0044 \\
\hline
\end{tabular}


150 , and $200 \mathrm{~cm}$ above the ground. The mobile anemobiagraph station was located at 12 sites distributed evenly along the Yellow River. Every observation lasted 4-8 hours.

The roughness length $z_{0}$ indicates the magnitude of the wind-velocity decrease caused by a surface and was obtained based on measured wind profiles over surfaces. When the atmospheric stability is neutral, the wind profile follows a logarithmic function and can be written as:

$$
u_{z}=\frac{u_{*}}{k} \ln \left(\frac{z-d}{z_{0}}\right) .
$$

Where, $u_{z}$ is the wind velocity at height $z, \mathrm{~m} / \mathrm{s} ; k$ is Von Karman's constant, $0.4 ; z$ is the measurement height, $\mathrm{m}$; and $d$ is the zero-plane displacement, which can be assumed to be zero during the windy season in the Ulanbuh Desert, where the vegetation cover rarely exceeds 20\% (Hoffmann et al., 2008). Equation 14 can therefore be rewritten as:

$$
u_{z}=\frac{u_{*}}{k} \ln (z)-\frac{u_{*}}{k} \ln \left(z_{0}\right) .
$$

Taking $u * / k$ as the slope and $-u * \ln \left(z_{0}\right) / k$ as the intercept, Eq. 16 can be written as a linear function which takes $\ln (z)$ as an independent value:

$$
u_{z}=a \ln (z)+b .
$$

Where, $a$ and $b$ are the fitting coefficients of the wind profile determined using observed data. By fitting the Eq. 16 using observed data, wind-profile equations for various surfaces could be obtained. The aerodynamic roughness length can be defined so that the height of the wind velocity is decreased to zero. Based on the concept of roughness length, when $u_{z}=0, z$ is similar to $z_{0}$. Therefore, the roughness length $z_{0}$ can be calculated as:

$$
z_{0}=e^{-b / a} .
$$

Based on the measured wind profiles, we calculated the roughness length value for every location.

The aeolian sediments were measured using sand traps with a height of $20 \mathrm{~cm}$. Every sand trap contains 10 sand channels, with every channel having a transverse section of $2 \mathrm{~cm} \times 2 \mathrm{~cm}$. The sand traps were placed downwind of the mobile anemobiagraph station. Four sand traps were set at each observation location, measuring intervals being 20 to $120 \mathrm{~min}$, and in total 76 saltation sediment processes were measured.

The aeolian sediments used in this research were described by the average values of sand collected from the four sand traps.

\section{Results}

\subsection{Frontal area of vegetation}

Observations of $N D V I$ and vegetation cover during the 2011 and 2012 windy seasons in the Ulanbuh Desert along the Yellow River were analyzed as described in the following sections.

The results of this research show that there was a significant correlation between $N D V I$ and vegetation cover during the 2011 and 2012 windy seasons. At this time, most vegetation had not yet sprouted, and therefore the ranges of the NDVI and vegetation cover values were narrow. However, vegetation cover and NDVI showed a significant correlation $\left(R^{2}=0.863\right)$. This relationship, observed during the green vegetation period, has also been seen in other arid or semi-arid regions (Honda, 1999; Kimura et al., 2009, 2010). The correlation coefficient between NDVI and vegetation cover for both withered and flourishing vegetation periods plotted together with the $N D V I$ was $R^{2}=0.9822$ (Fig. 3a).

This research used an equation proposed by Shao (1994) to calculate the frontal area, $\lambda$, using the vegetation cover as calculated from the NDVI data sets:

$$
\lambda=-c_{\lambda} \ln (1-V C) \text {. }
$$

Where $c_{\lambda}$ is an empirical coefficient based on observed data. For undergrowth, $c_{\lambda}=0.36$; for green vegetation, $c_{\lambda}=0.34$.

\subsection{Roughness length}

The roughness length $z_{0}$ can be expressed using the frontal area $\lambda$ and the vegetation height $h$ because a close relationship exists among these three variables. Several empirical or semi-empirical relationships among $z_{0}, \lambda$, and $h$ have been proposed (Lettau, 1969; Counihan, 1971; Theurer, 1973; Mariticorena et al., 1997; Macdonald et al., 1998; Shao and Yang, 2007). Because of disagreements among the equations and results obtained, it was difficult to determine which of the coefficients determined by others was best to use. Moreover, it was difficult to obtain vegetation height over an extensive area. From Table 2, it is apparent that vegetation height is highly variable in the Ulan- 
buh Desert. Shrubs in the Ulanbuh Desert include Seriphidium terrae-albae and Artemisia ordosica, which have a height range from 0.15 to $1 \mathrm{~m}$, and the grasses consist of wheatgrass, licorice grass, and Achnatherum splendens, with a height range from 0.09 to $1 \mathrm{~m}$. Therefore, in this study, a relationship was de- termined between the roughness length $z_{0}$ and the vegetation cover based on the authors' observed data and the work of previous researchers (Li et al., 2005; Kimura et al., 2010). The relationship between $z_{0}$ and vegetation cover showed a strong linear correlation $\left(R^{2}=0.9015\right)$ (Fig. 3b).
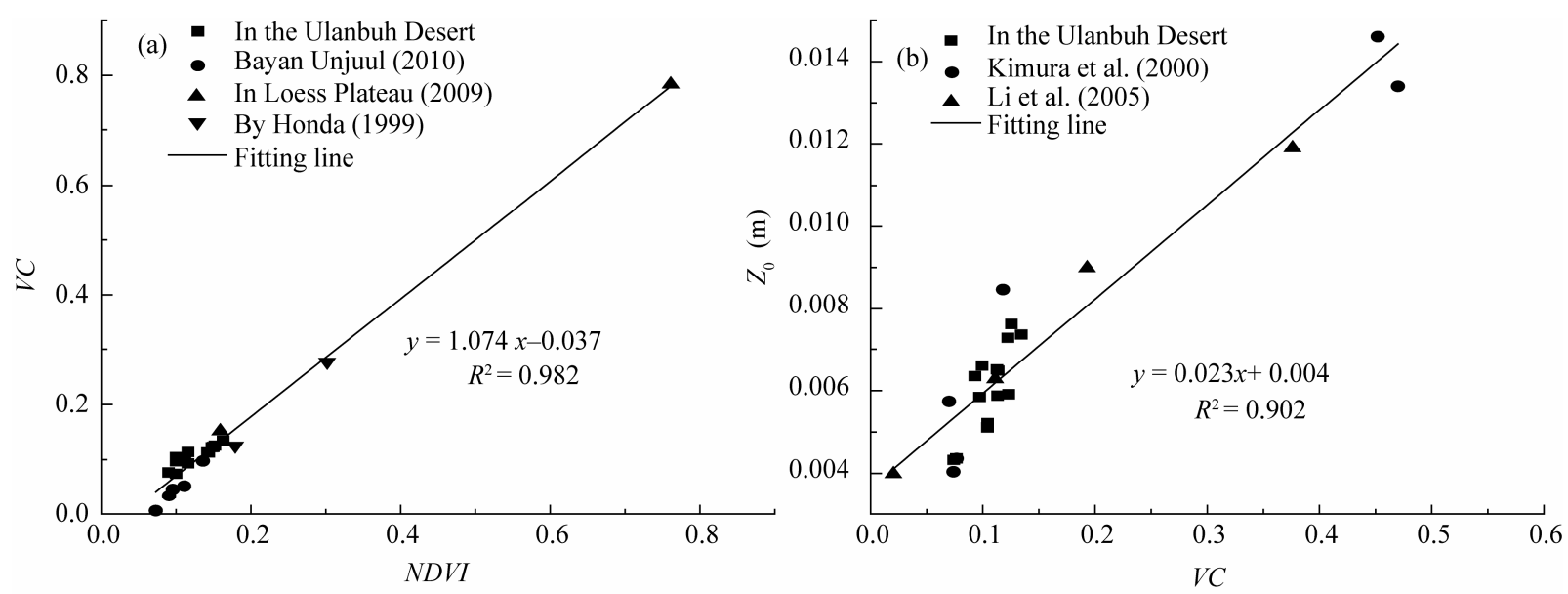

Fig. 3 Relationships among $N D V I$, vegetation cover $(V C)$, and roughness length $\left(z_{0}\right)$ : (a) relationship between $N D V I$ and vegetation cover; (b) relationship between roughness length $z_{0}$ and vegetation cover.

\subsection{Threshold wind velocity}

Determination of the threshold friction velocity for various vegetation conditions is difficult, requiring a large number of wind-tunnel experiments. However, this research introduces a simple testing method under the assumption that the cohesive force between fine sand particles, as expressed in Eq. 2, which incorporates the cohesive force, the aerodynamic force, and gravity, can be used. Equation 2 implies that $u_{*_{t}}$ is in general proportional to $\sqrt{Y_{1} d+Y_{2} d^{-1}}$ rather than to $\sqrt{d}$. The $Y_{2} d^{-1}$ term arises from the effect of interparticle cohesion. For large sand particles, the $Y_{1} d$ term dominates, and this implies that the balance between the aerodynamic force and the gravity force determines the magnitude of the threshold friction velocity. In this sand particle-size range, $u_{* t}$ increases with increasing sand particle size. For small particles, the $Y_{2} d^{-1}$ term dominates, and therefore the threshold friction velocity is determined by the balance between the aerodynamic and cohesive forces. The rapid increase of $u *_{t}$ with decreasing $d$ shows the strong effect of the cohesive force and the rapidly diminishing in- fluence of the gravity force.

Using Eq. 2, it was determined that the threshold wind velocity is smallest for sand particles with a diameter of $0.13 \mathrm{~mm}$. If Eq. 2 is suitable for threshold wind-velocity calculations, sand particles with diameter $0.13 \mathrm{~mm}$ will constitute the largest fraction in the sand traps. Figure 2 confirms the correctness of Eq. 2 . In the sand traps, the sand particle size group containing particles of $0.13 \mathrm{~mm}$ constitutes the largest fraction.

\subsection{Saltation sand flux model validation}

Using Eqs. 1-10, the saltation sand flux on the observation date was calculated. Then the sand-flux model was evaluated using the observed data and the statistical parameters $R M S E$ and absolute $R_{e}$ (Table 3 ).

Table 3 shows that both in sandy terrain and in grasslands, the saltation sand-flux model produced satisfactory results. All the values of RMSE are smaller than 0.05 , and the mean $\left|R_{e}\right|$ values are all less than $17 \%$.

It was also apparent from the results that in grasslands, $R M S E$ and mean $\left|R_{e}\right|$ increased with increasing 
Table 3 Statistical parameters of wind-erosion model in the Ulanbuh Desert

\begin{tabular}{cccc}
\hline $\begin{array}{c}\text { Number of } \\
\text { observation }\end{array}$ & Frontal area $\lambda$ & RMSE & Mean $\left|R_{e}\right|(\%)$ \\
\hline 7 & 0.5521 & 0.03542 & 12.09089 \\
5 & 0.5451 & 0.04293 & 15.81398 \\
6 & 0.4869 & 0.02039 & 9.47727 \\
7 & 0.5165 & 0.04810 & 16.77439 \\
5 & 0.4485 & 0.02150 & 11.90256 \\
8 & 0.3800 & 0.00777 & 7.72547 \\
9 & 0.5153 & 0.03780 & 16.72317 \\
6 & 0.4628 & 0.01541 & 12.43547 \\
9 & 0.4705 & 0.01904 & 13.36547 \\
6 & 0 & 0.02261 & 13.76741 \\
8 & 0 & 0.01934 & 5.74191 \\
\hline
\end{tabular}

frontal area $\lambda$. It is possible to speculate that the model's accuracy would decrease in grasslands with higher frontal area $\lambda$. It can also be seen that the observed sand-flux values are smaller than the simulated values in grasslands and that the divergence between the observed values and simulated ones increases roughly with increasing frontal area $\lambda$. These small divergences are probably due to soil moisture, which was ignored in the simulation because the soil of the Ulanbuh Desert is made up mainly of sand and the precipitation in the region is very low. In reality, along rivers, the vegetation cover is more flourishing than in other places, even in the windy season. Therefore, in these places, groundwater is close to the surface, and a small amount of water is contained in the soil. This small amount of soil moisture would increase the threshold friction velocity in these regions, and the actual saltation emissions in these places would be less than the calculated values. For this reason, the saltation sand-flux error increases with the frontal area $\lambda$.

\subsection{Subdaily wind velocities}

When the model was evaluated, the results were satisfactory. The wind velocity data used in the model were collected from the mobile anemobiagraph station. In other words, the wind velocities used for model evaluation have a higher time resolution than those collected from weather stations. Therefore, the accuracy of subdaily wind velocity simulated by WINDGEN must be verified. Synchronous wind velocity comparisons between the simulated hourly data and the values observed from the Wuhai and Dengkou weather stations from 1 April, 2012 to 30 April, 2012 were performed (Fig. 4). The simulated results of the three stations were all satisfactory, and the RMSE values of the simulation were 0.195 and 0.204 , respectively.

Based on the satisfactory simulation performance of the WINDGEN program, the hourly wind velocities of both stations were simulated.

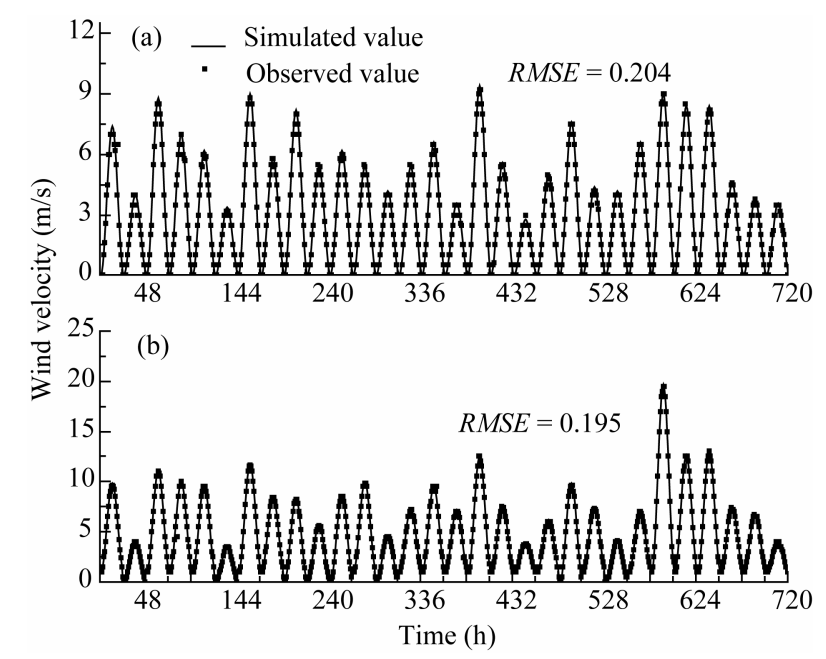

Fig. 4 Deviations of hourly wind velocity between simulated and observed values from 1 April, 2012 to 30 April, 2012: (a), deviations of hourly wind velocities at Dengkou station; (b), deviations of hourly wind velocities at Wuhai station.

\subsection{Quantity of aeolian saltation sediments depos- ited in the Yellow River}

Using the IWEMS saltation submodel and integrating RS (remote sensing) and GIS (geographic information system) technology, the authors performed quantitative measurements of saltation emissions in the Ulanbuh Desert along the Yellow River from 2001 to 2010.

Using Eq. 6, the daily amounts of saltation sediments entering the Yellow River from Wuhai to Dengkou were obtained (Fig. 5). Figure 5 showed that most of the aeolian saltation occurred in spring (from March to May), and little occurred in summer (from July to October) and winter (from December to February). The variation in daily saltation is very large. The largest amount, occurring on 25 April, 2010, was $6.54 \times 10^{5} \mathrm{t}$, but for most of the time, no saltation occurred in summer and winter. The saltation sediment yield is determined by the wind velocity and surface 


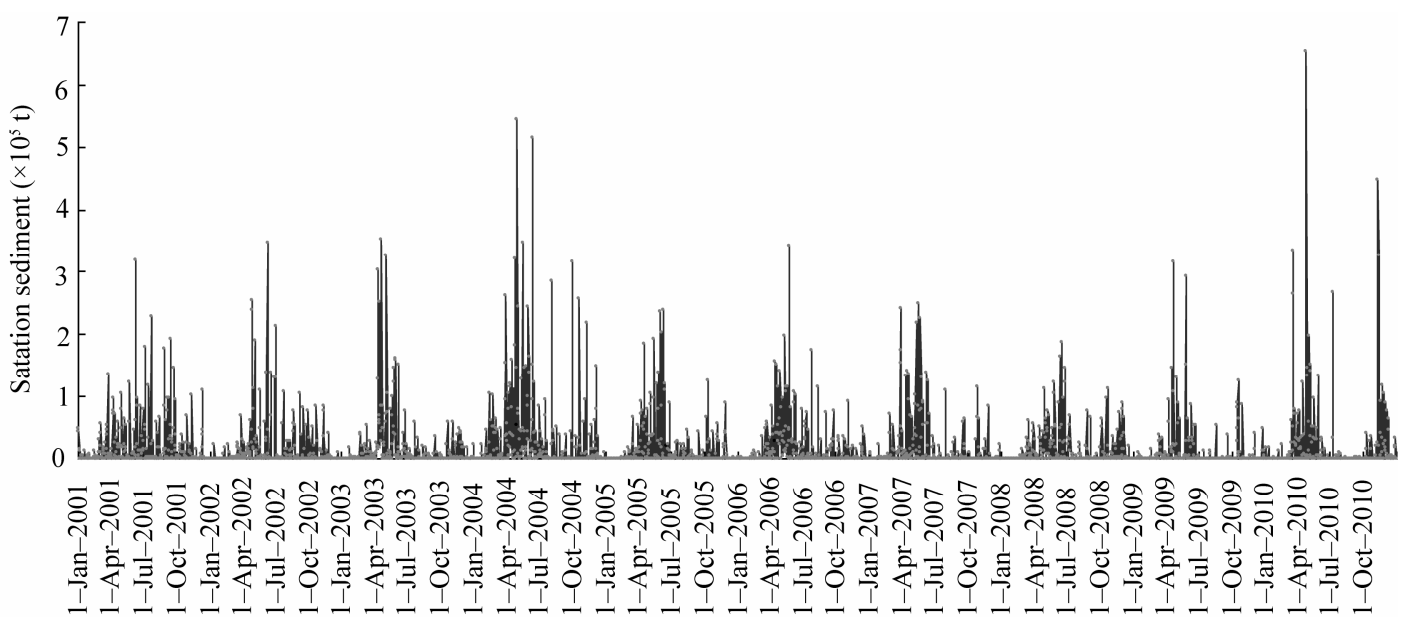

Fig. 5 Averaged daily amount of saltation sediments blown into the Yellow River from the Ulanbuh Desert from 2001 to 2010

vegetative conditions. In spring, strong winds occurred frequently and the vegetation cover was low; hence, most aeolian saltation occurred at this time. In winter, the surface vegetation cover was also low, but the wind velocity was not strong enough, and therefore the saltation emissions were very low. Summer brings higher vegetation cover and lower wind velocity, which caused little saltation emission in this season.

In the ten years from 2001 to 2010, the average annual amount of saltation sediments deposited in the Yellow River was $5.56 \times 10^{6} \mathrm{t}$ (Fig. 6). The interannual variation of saltation sediment deposition was large. In 2004, an amount of saltation sediments exceeding $1 \times 10^{7}$ tons was blown into the Yellow River. However, only $3.29 \times 10^{6} \mathrm{t}$ of saltation sediments was blown into the river in 2009.

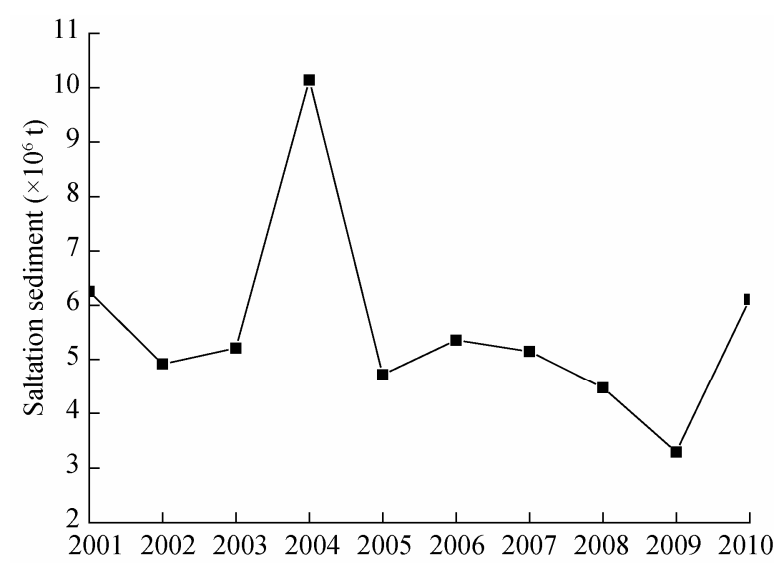

Fig. 6 Annual saltation sediments blown into the Yellow River from the Ulanbuh Desert from 2001 to 2010

\section{Discussion}

Currently, few wind-erosion models are used in China because the surface parameters have seldom been obtained and calibrated. Some research into wind erosion estimation has been performed using the ${ }^{137} \mathrm{Cs}$ tracer method (Yan et al., 2003; Hu et al., 2005) or has been limited to empirical equations covering a small area (Su et al., 2004; Bao et al., 2007; Huang et al., 2007).

According to the model developed here, the Ulanbuh Desert is a major source of aeolian sediments feeding the Yellow River. Yang et al. (1987) estimated that the mean annual supply of aeolian sand from the Ulanbuh Desert to the Yellow River was $1.91 \times 10^{7} \mathrm{t}$, while the local water conservancies estimated that the mean annual aeolian sediments feeding the Yellow River increased to $2.86 \times 10^{7} \mathrm{t}$ from 2000 to 2009 . These values are much larger than those obtained in this study. The major reason is that we did not calculate the avalanching of dunes caused by lateral water erosion. However, we doubted the accuracy of the value estimated by the local water conservancies. According to our field investigation, avalanching of dunes is very rare in the Ulanbuh Desert because the dunes along the Yellow River are very low and their slopes are gentle. The only obvious avalanching of dunes in this region took place in Wulan village, located to the north of Wuhai city, Inner Mongolia, but the length of the river bank where the avalanching occurred does not exceed $500 \mathrm{~m}$. Therefore, the major supply of aeolian sand for the Yellow River is not avalanching of dunes, but sand flux. 
In the simulation process, we found that most of the saltation emissions occurred in two sites along the Yellow River: one about $500 \mathrm{~m}$ in length located to the north of Wuhai city, and the other in the interval between Liuguaishatou in Dengkou county and Jiangui village, which has a length of $30 \mathrm{~km}$. Based on this situation, blown-sand protective systems should be built in these two sites to prevent the aeolian sediments from blowing into the Yellow River.

The quantity of aeolian saltation sediments blown into the Yellow River from the Ulanbuh Desert has been estimated; however, there are several paradoxical problems in this study.

First, IWEMS is a physically based model. To make use of quickly updated remote-sensing data and to simplify the calculations, several empirical equations were proposed to calculate frontal area, roughness length, and vegetation cover during the study period. The use of these empirical equations implies that the authors cannot explain the physical meaning and dimension of these empirical coefficients, which means that it would be difficult to extend the application of these empirical equations to other regions. However, remote-sensing data are characterized by easy access and quick update, which could make up for the lack of observations in the Ulanbuh Desert along the Yellow River. The results calculated by these empirical equations are all satisfactory compared with the observed data. Therefore, using remote sensing data in wind-erosion models can be regarded as a useful approach.

Second, the spatial resolution of the NDVI data set is coarse, and spatial heterogeneity inevitably exists within pixels. The frontal area $\lambda$, the roughness length $z_{0}$, and the threshold friction velocity $u_{*_{t}}$ were calculated on the basis of the NDVI data set. Therefore, it can be expected that errors exist in these parameters. Spatial heterogeneity is normally caused by two factors: the natural quality of the object, and the size of the measurement scales. Spatial heterogeneity would obviously change if the objects measured were at different scales (Chen et al., 2003). The spatial heterogeneity discussed in this paper was caused by the measurement scales. In recent years, remote sensing data have been widely used, and the spatial heterogeneity caused by measurement scales has been discussed by various researchers. For example, Toll (1985) classi- fied suburbs based on TM and MSS images and found that the classification accuracy using MSS images was lower than that using TM images by approximately $9 \%$. Based on the technology of decomposition of mixed pixels, Zhang et al. (2008) proposed a new method to change the spatial scales of the leaf area index in the Heihe River basin. The results showed that the scale error caused by nonlinear calculations and the error in the leaf area index caused by spatial heterogeneity could be as high as $45 \%$. NDVI data sets were also used to estimate the vegetation cover and frontal area by previous researchers (Honda, 1999; Kimura et al., 2009, 2010), in those works, the estimated error caused by spatial heterogeneity could be as high as $20 \%$. In this research, an NDVI data set with the same spatial resolution as the previous data was used, and the coefficients of determination in this research are higher than in previous papers. Therefore, it can be assumed that the estimated error should not exceed $20 \%$, which is an acceptable simulation error.

Third, the flexibility and porosity of the vegetation, which would impact the roughness length and the threshold friction velocity, were ignored. A calculation of threshold friction velocity with a roughness element, based on the theory of solid-element shelter, was proposed by Raupach (1993). Grant and Nickling (1998) demonstrated that the drag coefficients of porous elements were greater than those of solid-element forms with the same physical dimensions. Therefore, some error may exist in the simulation. However, in this study, we reduced the error due to roughness length and threshold friction velocity to as small a value as possible given the observed data. Therefore, although Raupach's model (1993) was used, satisfactory simulated results were obtained.

\section{Conclusions}

Using the IWEMS saltation submodel, the saltation process was simulated in the Ulanbuh Desert along the Yellow River to determine the quantity of aeolian sediments blown into the Yellow River. The mean annual quantity of saltation sediments blown into the Yellow River has been as high as $5.56 \times 10^{6} \mathrm{t}$ during the period from 2001 to 2010 . Through comparison with the values provided by local water conservancies, the present results have been determined to be more credible. 
The IWEMS saltation submodel used in this paper has a moderate spatial and temporal resolution (250 $\mathrm{m} \times 250 \mathrm{~m}, 10$-day interval) and is based on physical theories. In the absence of available observations and information for the Ulanbuh Desert, several empirical equations were introduced to calculate the vegetation's frontal area and roughness length. The results showed trends similar to previous research.

In this study, the daily quantity of aeolian sediments blown into the Yellow River was obtained. Three paradoxical problems existed and were described in

\section{References}

Anderson R S, Haff P K. 1991. Wind modification and bed response during saltation of sand in air. Acta of Mechanical (Suppl. 1): 21-51.

Baas A C W, Nield J M. 2007. Modelling vegetated dune landscapes. Geophysical Research Letters, 34: L06405.

Baddock M C, Livingstone I, Wiggs G F S. 2007. The geomorphological significance of airflow patterns in transverse dune interdunes. Geomorphology, 87(4): 322-336.

Bagnold R A. 1941. The Physics of Blown Sand and Desert Dunes. London: Chapman and Hall.

Böhner J, Schäfer W, Conrad O, et al. 2003. The WEELS model: methods, results and limitations. Catena, 52(4): 289-308.

Callot Y, Marticorena B, Bergametti G. 2000. Geomorphologic approach for modelling the surface features of arid environments in a model of dust emissions: application to the Sahara desert. Geodinamica Acta, 13(5): 245-270.

Chen Y F, Dong M. 2003. Spatial heterogeneity in ecological systems. Acta Ecologica Sinica, 23(2): 346-352.

Coen G M, Tatarko J, Martin T C, et al. 2004. A method for using WEPS to map wind erosion risk of Alberta soils. Environmental Modelling \& Software, 19(2): 185-189.

Couniban J. 1971. Wind tunnel determination of the roughness length as a function of the fetch and the roughness density of three-dimensional roughness elements. Atmospheric Environment, 5: 637-642.

Dong Z B, Gao S Y, Dong G R. 1999. A review of wind erosion prediction research. Journal of Desert Research, 19(4): 312-317.

Dong Z B, Fryrear D W, Gao S Y. 2000. Modeling the roughness effect of blown-sand-controlling standing vegetation in wind tunnel. Journal of Desert Research, 20(3): 260-263.

Fryrear D W, Saleh A, Bilbro J D, et al. 1998. Revised Wind Erosion Equation. USDA, ARS, Technical Bulletin No. 1.

Gillette D A, Stockton P H. 1989. The effect of nonerodible particles on wind erosion at erodible surface. Journal of Geophysical Research, 94: 12885-12893.

Greeley R, Iversen J D. 1985. Wind as a Geological Process on Earth, Mars, Venus and Titan. New York: Cambridge University Press.

Gregory J M, Wilson G R, Singh U B, et al. 2004. TEAM: integrated, process-based wind-erosion model. Environmental Modelling \& Software, 19(2): 205-215. the preceding section. However, through discussion of these problems, we found that they could not be overcome easily because of the lack of observations and studies in the Ulanbuh Desert, and that the simulated error had been reduced as far as possible. This means that this research has a substantial significance for practical application.

\section{Acknowledgements}

This work was financially supported by the National Key Basic Research Program of China (2011CB403306).

Hagen L J. 1991. A wind erosion prediction system to meet users need. Journal of Soil and Water Conservation, 46: 106-111.

He J L, Zhang S H, Cui W, et al. 2011. Monitoring and research on aeolian sand flow into Yellow River from Ulan Buh desert in Inner Mongolia. China Water Resources, 10: 46-48.

Honda Y. 1999. Development of estimation method for vegetation biomass using satellite observation. In: Report of CREST by Japan Science and Technology Agency, TN-1161, Japan.

$\mathrm{Hu}$ Y F, Liu J Y, Zhuang D F, et al. 2005. Caesium-137 distribution and estimation of wind erosion rate on the soil profile. Chinese Science Bulletin, 50 (9): 933-937.

Huang G B, Yu A Z, Guo Q Y, et al. 2007. Wind tunnel experiment on effect of conservative tillage in winter wheat fields on soil wind erosion in Hexi Corridor, Gansu province. Acta Pedologica Sinica, 44(6): 968-973.

Kimura R, Bai L, Wang J. 2009. Relationships among dust outbreaks, vegetation cover, and surface soil water content on the Loess Plateau of China, 1999-2000. Catena, 77(3): 292-296.

Kimura R, Shinoda M. 2010.Spatial distribution of threshold wind velocity for dust outbreaks in northeast Asia. Geomorphology, 114: 319-325.

Lettau H H. 1969. Note on aerodynamic roughness-parameter estimation on the basis of roughness element description. Journal of Application Meteorologica, 8: 828-832.

Li F R, Kang L F, Zhang H, et al. 2005. Changes in intensity of wind erosion at different stages of degradation development in grasslands of Inner Mongolia, China. Journal of Arid Environments, 62(4): 567-585.

Lu H, Shao Y P. 2001. Toward quantitative prediction of duststorms: an integrated wind erosion modelling system and its applications. Environmental Modelling \& Software, 16(3): 233-249.

Lyles L, Allison B E. 1976. Wind erosion: the protective role of simulated standing stubble. Transactions of the American Society Agricultural Engineers. 19: 61-64.

Macdonald R W, Griffiths R F, Hall D J. 1998. An improved method for estimation of surface roughness of obstacle arrays-a comparative study of the land use and built form of 110 schemes. Atmospheric Environment, 32: 3845-3862. 
Marshall J K. 1971. Drag measurement in roughness arrays of varying density and distribution. Agricultural Meteorology, 8: 269-292.

Marticorena B, Chazette P, Bergametti G, et al. 2004. Mapping the aerodynamic roughness length of desert surfaces from the POLDER/ADEOS bi-directional reflectance product. International Journal of Remote Sensing, 25: 603-626.

McKenna Neuman C. 2003. Effects of temperature and humidity upon the entrainment of sedimentary particles by wind. Boundary-Layer Meteorology, 108: 61-89.

Mu Q S, Wang J C, Miao T D. 2003. On the dynamical characteristic of roughness in the turbulent boundary layer. Acta Mechanical Sinica, 35(2): 129-134.

Musick H B, Gillette D A. 1990. Field evaluation of relationship between a vegetation structural parameter and sheltering against wind erosion. Land Degradation Rehab, 2: 87-94.

Okin G S. 2005. Dependence of wind erosion and dust emission on surface heterogeneity: stochastic modeling. Journal of Geophysical Research, 110: D11208.

Oldeman L R. 1994. The global extent of soil degradation. In: Greenland D J, Szabolcs I. Soil Resilience and Sustainable Land Use. CAB International, 99-118.

Omuto C T, Vargas R R, Alim M S, et al. 2010. Mixed-effects modeling of time series NDVI-rainfall relationship for detecting human-induced loss of vegetation cover in dry land. Journal of Arid Environments, 74: 1552-1563.

Owen R P. 1964. Saltation of uniform grains in air. Journal of Fluid Mechanics, 20: 225-242.

Prospero J M, Ginoux P, Torres O, et al. 2002. Environmental characterization of global sources of atmospheric soil dust identified with the Nimbus 7 Total Ozone Mapping Spectrometer (TOMS) absorbing aerosol product. Reviews in Geophysics, 40 (1): 1-26.

Raupach M R, Gillette D A, Leys J F. 1993. The effect of roughness elements on wind erosion threshold. Journal of Geophysical Research, 98(D2): 3023-3029.

Reffet E, Courrech du Point S, Hersen P, et al. 2010. Formation and stability of transverse and longitudinal sand dunes. Geology, 38(6): 491-494.

Shao Y P, Li A. 1999. Numerical modeling of saltation in atmospheric surface layer. Boundary-Layer Meteorology, 91: 199-225.

Shao Y P, Lu H. 2000. A simple expression for wind erosion threshold friction velocity. Journal of Geophysics Research, 105(22): 437-443.

Shao Y P. 2001. A model for mineral dust emission. Journal of Geophysics Research, 106(20): 239-254.

Shao Y P, Yang Y. 2007. A theory for drag partition over rough surface.
Journal of Geophysical Research: Earth Surface, doi: 10.1029/2007 JF000791.

Shao Y P. 2008. Physical and Modeling of Wind Erosion. Berlin of Germany: Springer Press.

Skidmore E L, Tatarko J. 1990. Stochastic wind simulation for erosion modeling. Transaction of ASAE, 33(6):1893-1899.

Su P X, Zhao A F, Du M W. 2004. Functions of different cultivation models in oasis agriculture on soil wind erosion and soil moisture conservation. Chinese Journal of Applied Ecology, 15(9): 1536-1540.

Theurer W. 1973.Dispersion of ground-level emissions in complex built-up areas. Ph.D. Thesis, Karlsruhe: University of Karlsruhe.

Thomann RV. 1982. Verification of water quality models. Journal of Environmental Engineering Division, 108(5): 923-940.

Toll D L. 1985. Preliminary study of information extraction from Landsat TM data for suburban/regional test site. Proceedings of Landsat-4 Science Characterization Early Results Symposium, Greenbelt, Maryland, NASA, 4: 387-402.

Van Pelt R S, Zobeck T M. 2004. Validation of the Wind Erosion Equation (WEQ) for discrete periods. Environmental Modelling \& Software, 19(2): 199-203.

Visser S M, Sterk G, Karssenberg D. 2005. Wind erosion modelling in a Sahelian environment. Environmental Modelling \& Software, 20(1): 69-84.

Wang Q, Tenhunen J, QuocDinh N, et al. 2004. Similarities in ground-and satellite-based NDVI time series and their relationship to physiological activity of a Scots pine forest in Finland. Remote Sensing of Environment, 93: 225-237.

Webb N P, McGowan H A, Phinn S R, et al. 2006. AUSLEM (Australian Land Erodibility Model): a tool for identifying wind erosion hazard in Australia. Geomorphology, 78(3-4): 179-200.

Woodruff N P, Siddoway F H. 1965. A wind erosion equation. Soil Science Society of America Proceedings, 29(5): 602-608.

Yan P, Dong G R, Zhang X B, et al. 2003.Application of Caesium-137 technique on wind erosion in Gonghe Basin, Qinghai provice (II). Journal of Desert Research, 23(4): 391-397.

Yang G S, Liu Y, Shi P J. 1987.Estimation of the aeolian sand entering the Yellow River. Chinese Science Bulletin, 13: 1017-1021.

Yao Z Y, Ta W Q, Jia X P, et al. 2011. Bank erosion and accretion along the Ningxia-Inner Mongolia reaches of the Yellow River from 1958 to 2008. Geomorphology, 127: 99-106.

Yen B C. 1993.Criteria for evaluation of watershed models. Journal of Irrigation Drainage Engineering, 119(3): 429-442.

Zhang W C, Zhong S, Hu S Y. 2008. Spatial scale transferring study on Leaf Area Index derived from remotely sensed data in Heihe River Basin, China. Acta Ecological Sinica, 28(6): 2495-2503. 